\title{
Application of Artificial Neural Network for Design of Two Way Slab \\ ${ }^{1}$ Anushka Kumar, ${ }^{\text {2}}$ P.D.Pachpor, ${ }^{3}$ A.K.Sharma \\ 1,2,3 Civil Department, Shri Ramdeobaba College of Engineering and Management, Nagpur \\ Email: pachporpd@rknec.edu, anushkakumar432@gmail.com,sharmaak@rknec.edu
}

Received: 20th November 2019, Accepted: 10th February 2020, Published: 29th February 2020

\begin{abstract}
Design of reinforced concrete slab subjected to load requires understanding of design philosophy and detailed knowledge of reinforced concrete structure. The support conditions, loading pattern, span dimensions in both the directions, grade of concrete etc are the governing issues for deciding thickness and reinforcement in both directions. Various charts, tables are available for references in IS code456, for designing of slabs. Use of such charts and tables are tedious and interactive approach is required for economical designing. Artificial neural network is one of the tool to get proper processing of data and obtaining required results by effective training of network. In present paper, several data is prepared and developed using spreadsheet for various end conditions and spans. Total 51 cases are studied in each 9 end conditions and tabulated for training and 12 cases are tested for expected output of thickness and amount of steel. Results are comparable with analytical one with least $\%$ of error.
\end{abstract}

\section{Keywords}

Two Way Slab, Aspect Ratio, Artificial Neural Network

\section{Introduction}

An Artificial Neural Network (ANN) is an information processing paradigm that is inspired by the way biological nervous system such as brain process information. The key element of this paradigm is the novel structure of the information processing system. In Civil Engineering, there are a number of situation where we have sufficient data in the form of design aids, chart and tables but the use of these data requires mutual reading of the data and the development fully computer based program and design procedures becomes difficult. On the other hand, by using available data, the ANN can be trained and once the training is over, the develop network can be used in the design procedure. [4] For two way slab design we require to refer the various tables and charts IS 456-2000 which becomes a very tedious process. But by using Artificial Neural Network, we can reach to conclusion immediately. Development of computer aided design procedure for the design of RCC two way slab for various end conditions using Artificial Neural Network is taken as the main objective.

\section{Neural Network}

An Artificial Neural Network is basically an information processing paradigm that is inspired by the way biological nervous systems, such as the brain, process the information. The key element of this paradigm is the novel structure of the information processing system. It is composed of large number of highly interconnected processing elements (neurons) working in unison to solve specific problems, such as pattern recognition or data classification, through a learning process. Learning in biological systems involves adjustments to the synaptic connections that exist between the neurons. [1]

\section{Structure of Artificial Neural Network}

An ANN is defined as a highly interconnected network of small processing unit called 'neurons'.

A neuron is an adoptive mode and is smallest part of the brain. The modes of the brain are adaptable, in the sense, they acquire knowledge through changes in the functions made by been exposed to example. Neurons are represented by small triangles. Neurons which have similar characteristics are grouped into one layer. There are basic three layers in an ANN: Namely input layer, hidden layer, output layer .Each neuron in the input layer receives an excitation (or input) from the external source. The set of input values is called the input vectors. Each neuron in one layer is connected to the other neuron in the adjacent layer, by what is known as "connection strength" or 'weight'. The weights are represented by lines. The connection strength or weights define the relationship between the neurons. [3,5]

Applications of Artificial Neural Network

Neural networks are applicable in virtually every situation in which a relationship between the predictor variables (independents, inputs) and predicted variables (dependents, outputs)exists, even when that relationship is very complex and not easy to articulate in the usual terms of "correlations" or differences between groups". $[2,6,7]$ A few representative examples of problems to which neural network analysis has been applied successfully are:

Application in Civil, Structural and Earthquake Engineering

- Modeling the seismic hazard assessment.

- Repair, rehabilitation and retrofitting of structures. 
- Multilayer perception in damage detection of bridge structures.

- Direct identification of structural parameters from dynamic responses with neural networks.

- Nonlinear dynamic analysis.

- Stochastic earthquake analysis.

- Seismic hazard assessment.

- Vibration control.

Geotechnical Engineering

- Foundation engineering

- Numerical modelling of foundation and retaining structures.

- Geosynthetics -reinforced soil structures.

- Soil-structure interaction problems.

- Slope stabilization and soil reinforcements.

- Ground improvement.

Transportation Engineering

- Traffic analysis and design.

- Road safety and traffic congestion.

- Travel demand modelling and forecasting.

- Traffic flow theory and capacity analysis and traffic flow modelling and simulation.

- Urban land modelling and forecasting.

\section{Environmental Engineering}

- Analysis of initiation of sediment suspension from bed load.

- Sediment load and sediment transport amount for surface water.

- Sediment data and sediment transport amount for surface water.

- Generalised regression neural network in modelling river sediment yield.

\section{Remote Sensing and Photogrammetric Engineering}

- Geographic information system.

- Remote sensing and space geodesy.

- Surveying.

Design of Two Way Slab (As Per IS 456-2000) :

- Check for Aspect ratio i.e. is the length of longer span to the length of smaller span should be less than 2 for two way slab condition.

- Using design constants \% of steel is determined.

- Loading calculations and effective span is determined by using width of column.

- Bending moment calculations using Table 26 IS 456-2000-Bending Moment coefficients for rectangular panels supported on four sides with provision for Torsion at corners.

- Using moments main reinforcement is calculated and $\mathrm{Ast}_{\min }=0.12 \%$ of $\mathrm{BxD}$.

\section{Methodology}

In present paper following methodology has been used;

1. Designing a two way RCC for suitable data by standard method.

2. Analysis and comparison by ANN

\section{Design Example:}

Size of room $=4 \times 5 \mathrm{~m}$, Live load $=3 \mathrm{kN} / \mathrm{m}^{2}$ and floor finish load $=0.5 \mathrm{kN} / \mathrm{m}^{2}$

Aspect Ratio $=l y / l x=5 / 4<2, \quad$ Thus, two way slab.

Design Constants: $\mathrm{Fck}=20 \mathrm{~N} / \mathrm{mm}^{2} \quad \mathrm{Fy}=415 \mathrm{~N} / \mathrm{mm}^{2}$

$\mathrm{Mu}_{\mathrm{lim}}=0.138 \times \mathrm{fck} \times \mathrm{bd}^{2}$

$\left.\mathrm{P}_{\text {tlim }}=(0.36 * f c k *(x u m a x) * 100) / 0.87 * f y * d\right)$

Effective Depth

$L x / d=$ B.V. $\times$ m.f.

$\mathrm{d}=160 \mathrm{~mm}, \quad \mathrm{D}=180 \mathrm{~mm}$

Loading Calculations

D.L. $=\mathrm{bD} \gamma=1.0 \times 0.18 \times 25=4.5 \mathrm{kN} / \mathrm{m}^{2}, \quad$ L.L. $=2 \mathrm{KN} / \mathrm{m}^{2}, \quad$ F.F. $=0.5 \mathrm{kN} / \mathrm{m}^{2}$

$\mathrm{W}=7 \mathrm{kN} / \mathrm{m}^{2}, \quad \mathrm{Wu}=10.5 \mathrm{kN} / \mathrm{m}^{2}$

Effective Span

Along shorter $\operatorname{span}=1 \mathrm{x}+\mathrm{d}$ so $=4+0.16=4.16 \mathrm{~m}$

Along longer $\operatorname{span}=1 \mathrm{y}+\mathrm{dy}$ so $=5+0.15=5.15 \mathrm{~m}$

Bending Moment Calculations

Ly/lx $=1.23$ 


\begin{tabular}{|l|l|c|}
\hline Ly/lx & \multicolumn{1}{|c|}{$\alpha_{\mathrm{x}}$} & $\alpha_{\mathrm{y}}$ \\
\hline 1.2 & 0.084 & 0.053 \\
\hline 1.23 & $\mathbf{0 . 0 8 6 7}$ & $\mathbf{0 . 0 5 6 2}$ \\
\hline 1.3 & 0.093 & 0.055 \\
\hline
\end{tabular}

Thus, by interpolation,

$\alpha_{x}=0.0867$

$\alpha y=0.0562$

$\mathrm{Mx}=\mathrm{Wu} \times \alpha \mathrm{x} \times \mathrm{Leff}^{2}=15.765 \mathrm{kN} . \mathrm{m}$

$\mathrm{My}=\mathrm{Wu} \times \alpha \times \times \mathrm{Leff}^{2}=10.21 \mathrm{kN} . \mathrm{m}$

Check for Depth

$\mathrm{Mu}=$ Mulim

$15.765 * 10^{6}=0.138 \times f c k \times b d^{2}$

$\mathrm{d}=75.54<160 \mathrm{~mm}$ thus, safe

Design of Main Reinforcement

Ast $=\left(\frac{0.5 f c k}{f y} *\left(1-\sqrt{1}-4.6 * \frac{M u}{f c k b d^{2}}\right) * b d\right.$

Ast $=117.93 \mathrm{~mm}^{2}$

The design of two war slabs was carried out for all the nine cases of support conditions of a continuous slab.

Some of the cases are shown below.

Sheet 1.0 Two Way Slab (All four edges continuous)

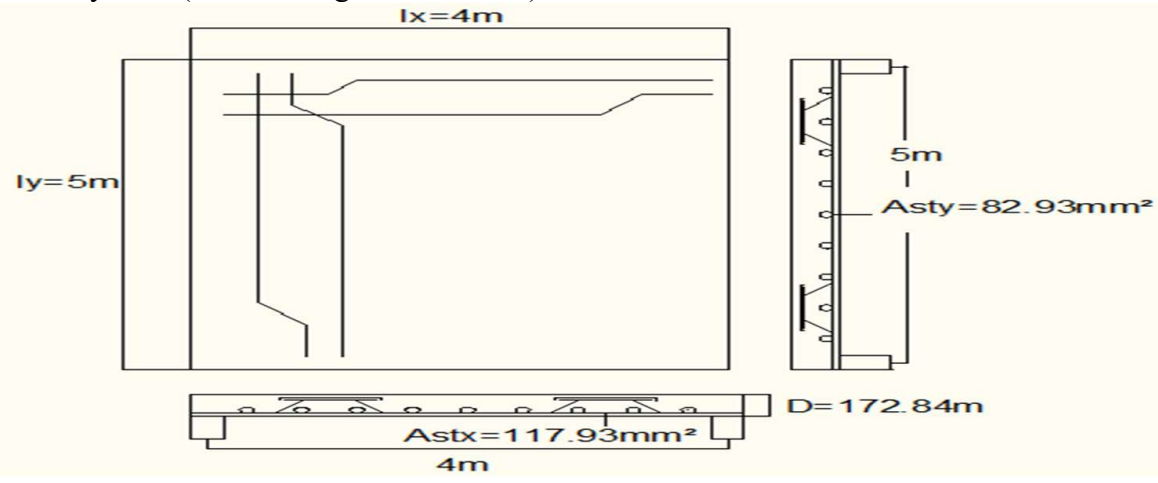

Figure 1: Reinforcement Details of Two way Slabs

\section{Result and Discussion}

Application of Design of Two Way RCC Slab in Neural Network

Following are the steps involved for various values of Ast for two way slab by Quasi Newton Method Case 1 (All four edges continuous)

\section{A) Analysis}

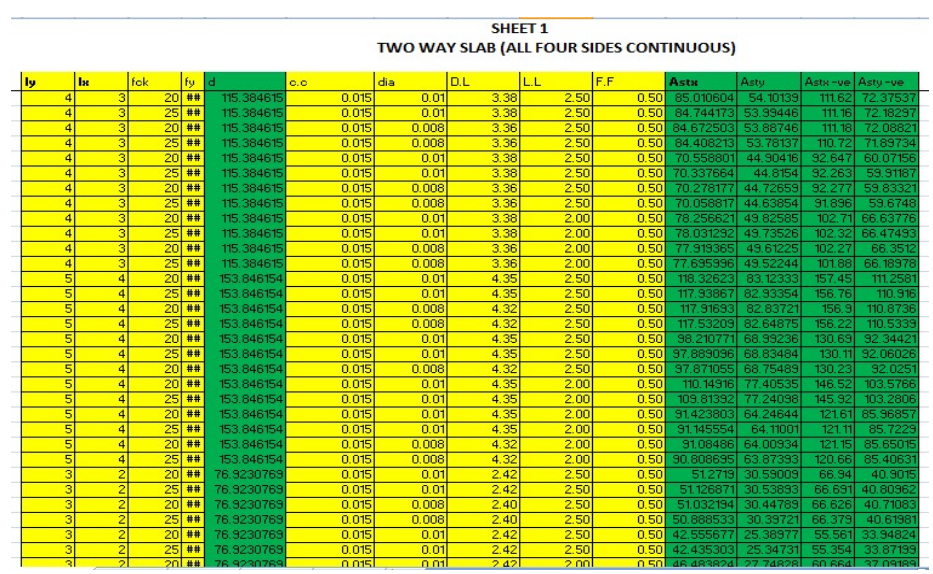

Figure 2 : Two Way Slab (All four edges continuous)

The analysis tab provides easy access to the tasks you may need to complete when analyzing a dataset and preparing it for pre-processing. You can quickly select a target column from the drop-down columns list at the toolbar. You can use Analysis Toolbar to specify column types, detect data anomalies, partition data, and exclude selected columns and rows. 


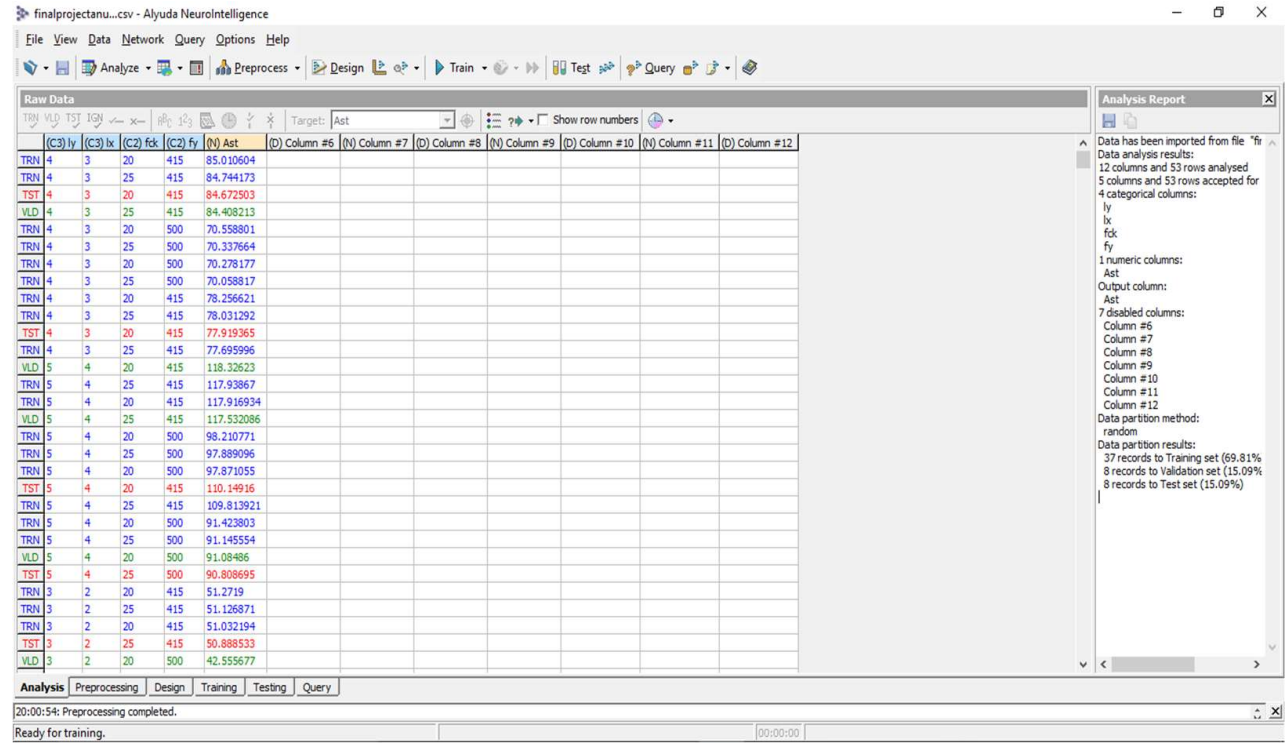

Figure 3: Analysis of Slab

\section{B) Preprocessing}

Pre-processing tab lets you inspect internal representation of your dataset. You will see scaled columns, encoded categorical and date/time ones as well as statistical details about each column.

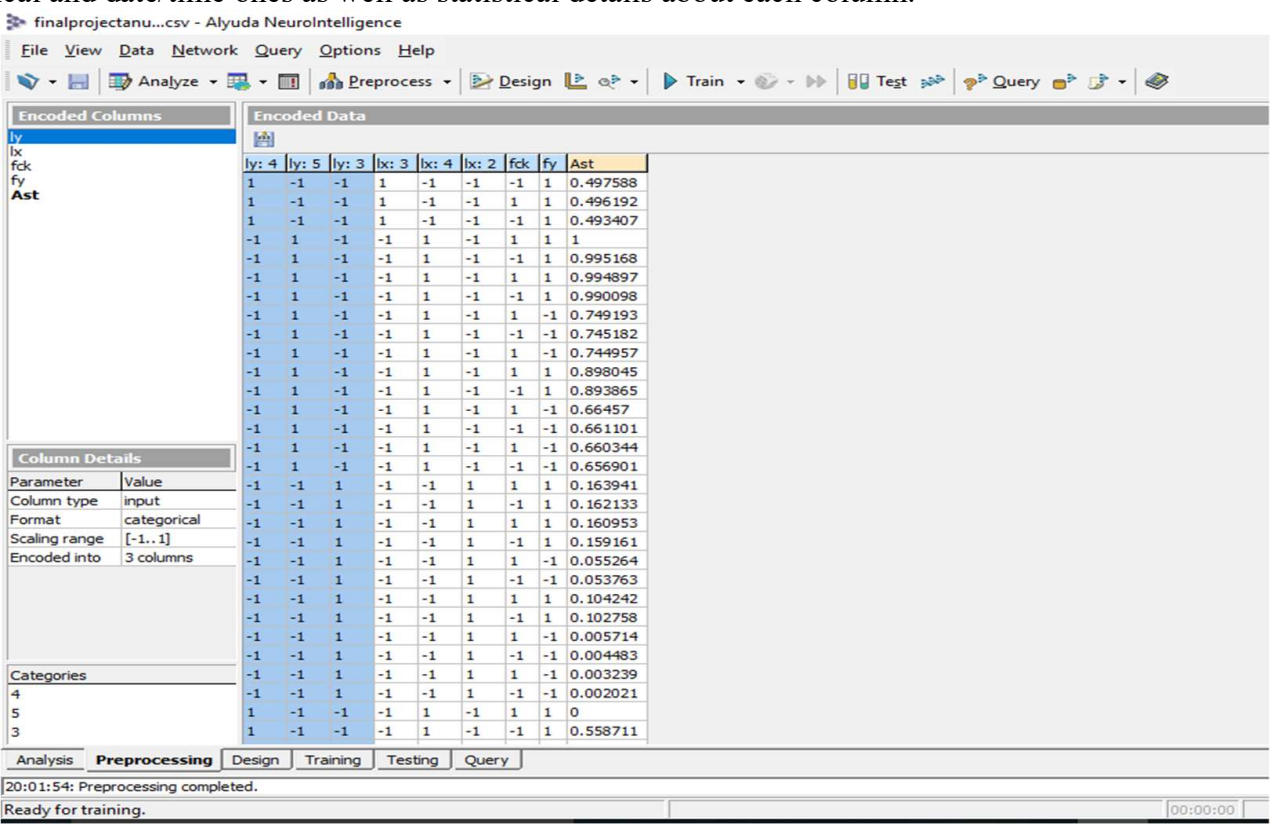

Figure 4: Preprocessing of Slab Data

\section{C) Design}

Design tab helps you to design the most efficient neural network architecture. You can run architecture search algorithms, manage network set and analyze training graphs and statistics for network candidates. Here you can also define activation and error function, classification model and accept/reject levels. 


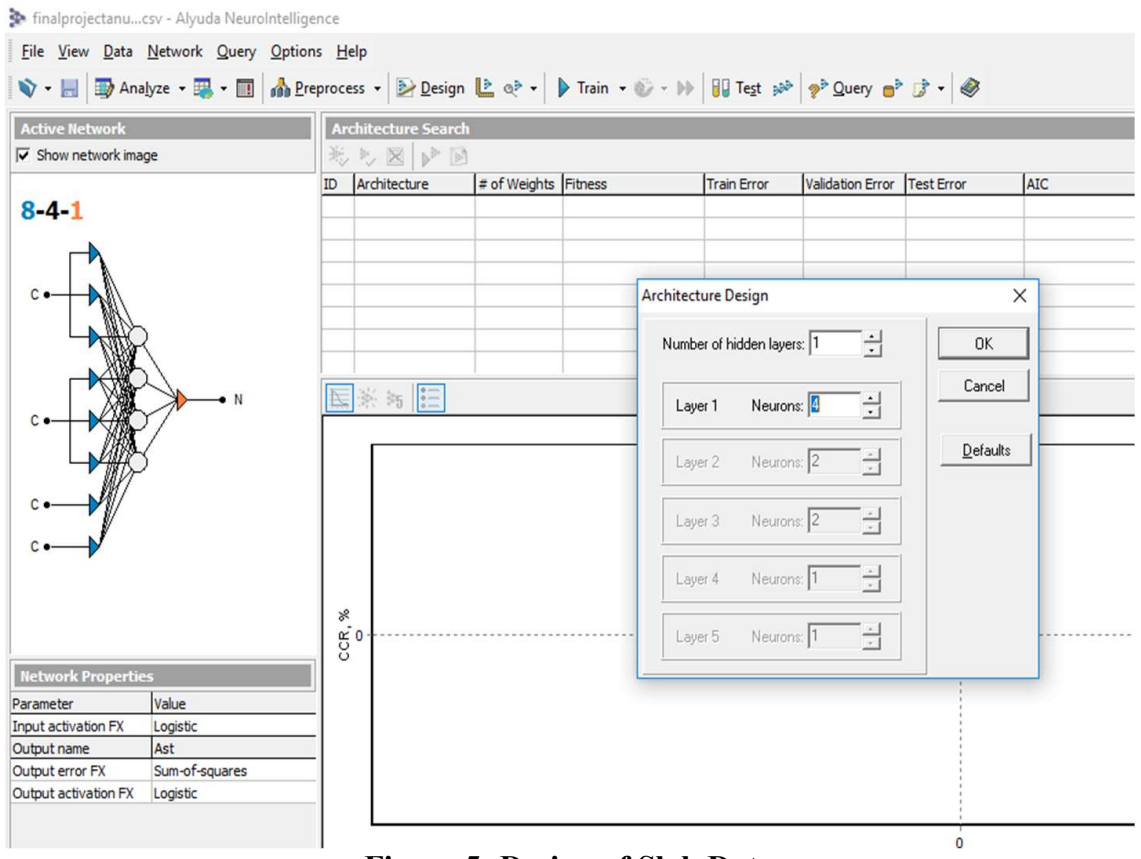

Figure 5: Design of Slab Data

\section{D) Training}

Training tab provides a visual representation of the training process. You can monitor the training with training graphs, error distribution and weights distribution histograms, input importance chart and real-time training details. We have trained our data by using Quasi Newton method. One laces iteration is given for our training data.

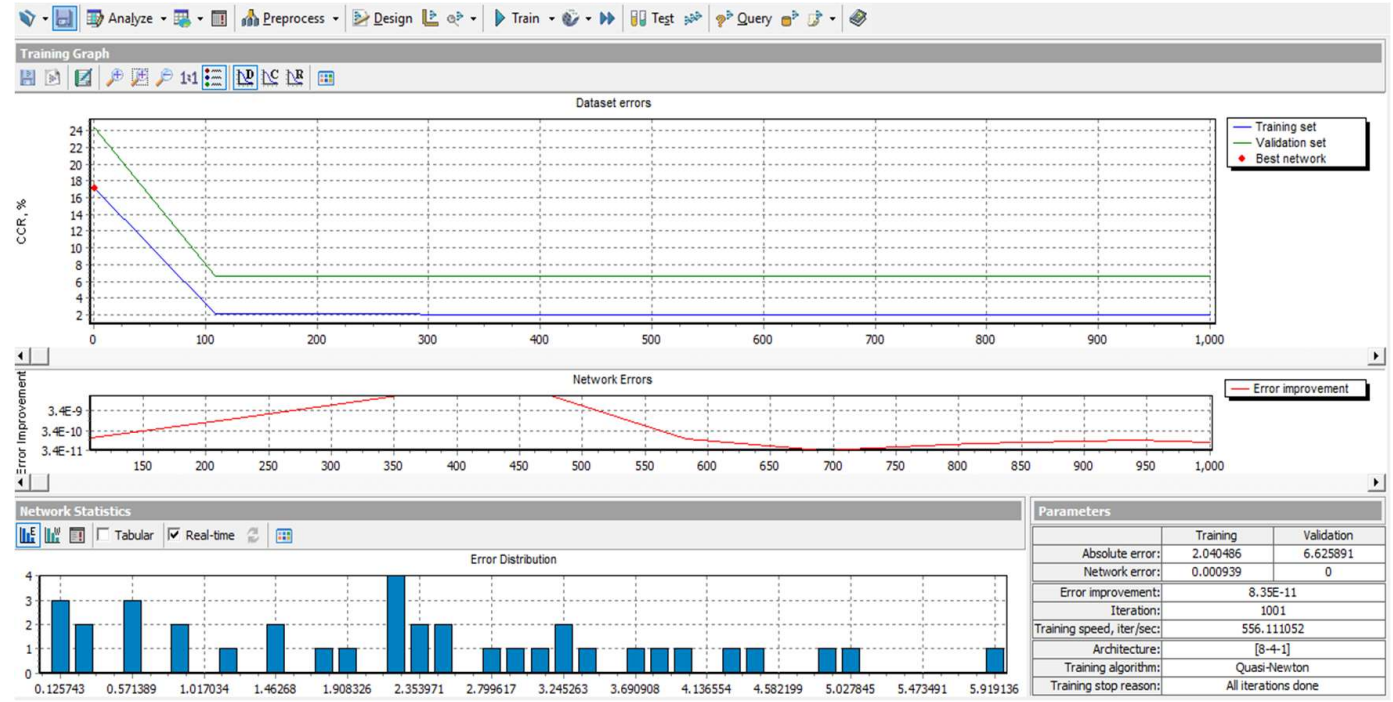

Figure 6: Training of Slab Data

\section{E) Testing}

Testing tab helps you analyse performance of the trained network. You can inspect Actual vs Output graph, scatter plot, response graph, confusion matrix and ROC curve. 


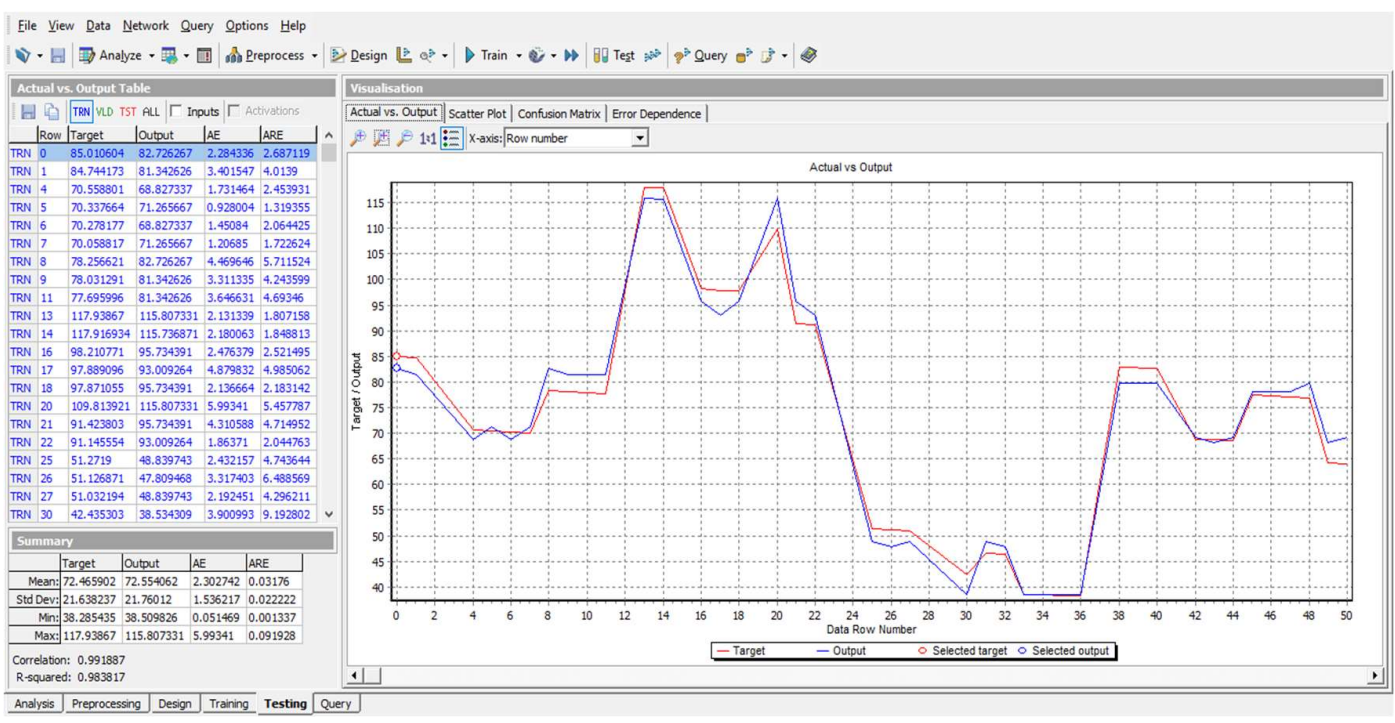

Figure 7 : Testing of Slab Data

\begin{tabular}{|l|l|l|l|l|l|}
\hline $\begin{array}{l}\text { Sr. } \\
\text { No. }\end{array}$ & Case no. & $\begin{array}{l}\text { Dimensions of } \\
\text { slab }\end{array}$ & Target value & $\begin{array}{l}\text { Output value } \\
\text { (Using ANN) }\end{array}$ & \% difference \\
\hline 01 & Interior Panels & $3 \mathrm{~m} \times 4 \mathrm{~m}$ & $85.010 \mathrm{~mm}^{2}$ & $82.72 \mathrm{~mm}^{2}$ & $2.69 \%$ \\
\hline 02. & $\begin{array}{l}\text { One short edge } \\
\text { continuous }\end{array}$ & $3 \mathrm{~m} \times 4 \mathrm{~m}$ & $103.49 \mathrm{~mm}^{2}$ & $97.419 \mathrm{~mm}^{2}$ & $5.86 \%$ \\
\hline 03. & $\begin{array}{l}\text { One long edge } \\
\text { discontinuous }\end{array}$ & $3 \mathrm{~m} \times 4 \mathrm{~m}$ & $116.27 \mathrm{~mm}^{2}$ & $110.33 \mathrm{~mm}^{2}$ & $5.108 \%$ \\
\hline 04. & $\begin{array}{l}\text { Two adjacent } \\
\text { edges } \\
\text { discontinuous }\end{array}$ & $3 \mathrm{~m} \times 4 \mathrm{~m}$ & $98.86 \mathrm{~mm}^{2}$ & $98.717 \mathrm{~mm}^{2}$ & $0.144 \%$ \\
\hline 05. & $\begin{array}{l}\text { Two short edges } \\
\text { discontinuous }\end{array}$ & $3 \mathrm{~m} \times 4 \mathrm{~m}$ & $133.13 \mathrm{~mm}^{2}$ & $132.504 \mathrm{~mm}^{2}$ & $0.47 \%$ \\
\hline 06. & $\begin{array}{l}\text { Two long edges } \\
\text { discontinuous }\end{array}$ & $3 \mathrm{~m} \times 4 \mathrm{~m}$ & $133.139 \mathrm{~mm}^{2}$ & $132.117 \mathrm{~mm}^{2}$ & $0.76 \%$ \\
\hline 07. & $\begin{array}{l}\text { Three edges } \\
\text { discontinuous(one } \\
\text { long edge } \\
\text { continuous) }\end{array}$ & $3 \mathrm{~m} \times 4 \mathrm{~m}$ & $155.26 \mathrm{~mm}^{2}$ & $156.102 \mathrm{~mm}^{2}$ & $0.54 \%$ \\
\hline 08. & $\begin{array}{l}\text { Three edges } \\
\text { discontinuous } \\
\text { (one short edge } \\
\text { continuous) }\end{array}$ & $3 \mathrm{~m} \times 4 \mathrm{~m}$ & $189.50 \mathrm{~mm}^{2}$ & $186.75 \mathrm{~mm}^{2}$ & $1.45 \%$ \\
\hline 09. & $\begin{array}{l}\text { All edges } \\
\text { discontinuous }\end{array}$ & $3 \mathrm{~m} \times 4 \mathrm{~m}$ & $189.503 \mathrm{~mm}^{2}$ & $186.75 \mathrm{~mm}^{2}$ & $1.45 \%$ \\
\hline
\end{tabular}

Table 1: Comparison of Results for Area of Steel

\section{Conclusion}

- For design of two way slabs for 9 cases of end conditions are studied and analysis has been done for approximately 60 variable data in each case for obtaining the value of Ast using MS-Excel.

- Total 9 cases of edge conditions of two way slabs are trained as sample data for ANN and accordingly training and testing is done and hence the results so obtained are shown in table 01.

- Result obtained from ANN for finding out Ast for two way slab have a percentage error of about 5\% when compared to manual calculations for the design of two way slabs.

- Best architecture for quasi newton method for design of two way slabs is 8-4-1.

- Thus the ANN model has immense potential to predict reasonably accurate values of area of reinforcement for two way slabs.

- The model can be used for all the general practical cases of two way slabs. 


\section{References}

1. Arslan, A and Ince, R (1994) "The Neural Network based design of edge supported reinforced concrete slabs" Artificial Intelligence and object-oriented approaches for structural engineering, civil comp press,91-97

2. Adel H, and ParkH.S.(1995)," Counter propogation Neural Networks in Structural Engineering" Journal of Structural engineering, ASCE, 128 (8),1205-1212

3. FloodI, and Karttam,N (1994) “Neural Network in civil engineering” Journal of computing in civil engineering, ASCE 8(2),131-147

4. IS 456-2000 (code of practice for general structural use of plain and reinforced concrete)

5. Mateuz Kaczmarek, Agnieszka Szymanska: "Application of artificial neural networks to predict the deflections of reinforced concrete slabs" studia geotechnical, vol. 38, no. 2, 2016

6. Shah and Kale "Textbook of R.C.C."

7. Susan Hentschel Tully: "A neural network approach for predicting the structural behaviour of concrete slabs". 